\title{
Porque (não) perguntam os alunos? Estudo exploratório
}

\author{
Why do (or don't) pupils ask questions? An exploratory research \\ P.Vaz-Rebelo ${ }^{1}$, J. Morgado ${ }^{2}$, P. Fernandes ${ }^{3}$, C. Barreira ${ }^{1}$, B. Jesus ${ }^{4}$, L. Cardoso ${ }^{4}$, R. Soares ${ }^{4}, \&$ B. Silva ${ }^{4}$ \\ ${ }^{1}$ Universidade de Coimbra, ${ }^{2}$ Escola Básica e Secundária Sta Maria do Olival, ${ }^{3}$ Agrupamento \\ de Escolas de Seia, ${ }^{4}$ Mestrado em Ensino da Matemática, Universidade de Coimbra. \\ Portugal
}

\section{Resumo}

Este estudo visa analisar as perceções de alunos sobre as razões que podem estar na base da formulação (ou não) de perguntas em contexto de aula. Participaram no estudo 85 alunos do $3^{\circ}$ ciclo do ensino básico, com idades compeendidas entre os 13 e 16 anos. A análise de conteúdo das respostas a um questionário de resposta aberta evidenciou que os alunos consideram muito importante o seu próprio questionamento e que formulam perguntas para esclarecer dúvidas e compreender melhor os assuntos. No entanto, referem também que raramente formulam perguntas em contexto de aula por vergonha, medo de ser ridicularizado ou insegurança quanto à pertinência da mesma.

Palavras-chave: perguntas dos alunos, barreiras ao questionamento, gestão da aula

\begin{abstract}
This study aims to analyze the perceptions of students about the reasons that promote questioning in class. 85 students from 3rd cycle of basic education participated in the study, aged between 13 and 16 years old. The content analysis of the responses to an open-response questionnaire showed that students consider very important their own questions and that they formulate questions to better understand the contents. However, they also note that rarely they ask questions in class context by shame, fear of being ridiculed or uncertainty about the relevance of it.

Key words: Students' questions, barriers opposing to questioning, class management
\end{abstract}

\section{Introdução}

Estudos prévios sobre as perguntas dos alunos têm evidenciado que estas são pouco frequentes, predominando habitualmente as perguntas do professor (Dillon, 1988). No entanto, há também evidências que apontam para o impacto positivo que as referidas perguntas pode ter no seu envolvimento e nas suas próprias aprendizagens. Justifica-se por isso o interesse em compreender os motivos que podem estar subjacentes à formulação de perguntas mas que também podem constituir possíveis barreiras ao processo.

Graesser, Person e Huber (1992) referem que o processo de questionamento dos alunos envolve três etapas: uma etapa de identificação de anomalias, associada à tomada de conscência de lacunas de conhecimento ou de incongruências no mesmo; uma outra. de elaboração da pergunta propriamente dita; e uma terceira, relacionada com os aspectos sociais associados à sua formulação.

Esta dinâmica do processo de questionamento pode ser influenciada por vários factores, por exemplo, o conhecimento prévio, os padrões de coerência ou a autoridade epistémica da fonte de informação (Otero \& Ishiwa, 2014; Vaz-Rebelo, Fernandes, Morgado, Monteiro, \& Otero, 2014). Chin e Osborne (2008), num estudo de revisão sobre o tema, referem também a influência de aspectos pessoais como a idade, competências individuais ou conhecimento prévio, enfatizando Pedrosa de Jesus, Teixeira-Dias e Watts (2003) a importância dos estilos de aprendizagem e da capacidade de tolerância ao risco e à incerteza (Pedrosa de Jesus, Almeida, \&Watts, 2004). De entre as variávies associadas aos aspectos sociais podem referir-se também as características do professor e do grupo-turma (Karabenick, 1996). Chin e Osborne (2008), no referido estudo de revisão sobre o tema, referem a influência das atitudes do professor, do seu estilo, da estrutura do reforço, do clima da aula e dos padrões de interação, enfatizando Pedrosa de Jesus et al. (2003) o papel das reações de professores e dos colegas ou as estruturas de suporte e das possíveis interações entre estas e as características dos alunos. Com efeito, a formulação de uma pergunta expõe o sujeito à apreciação do professor e do grupo, e esta exposição, assim como a avaliação do própria pergunta, pode constituir um obstáculo à sua formulação, que, no entanto, pode também ser experienciada de forma diferente em função de características de personalidade.

$\mathrm{O}$ presente estudo tem por objetivo analisar as perceções de alunos sobre as perguntas dos alunos, em particular as razões que podem estar na base da sua formulação ou justificar o seu evitamento.

\section{Método}

\section{Participantes}

O presente estudo foi desenvolvido numa amostra de 88 alunos do $3^{\circ}$ ciclo do ensino básico, com idades compeendidas entre 13 e 16 anos, sendo 37 raparigas e 51 rapazes.

\section{Instrumentos}

Foi utilizado um questionário de resposta aberta, incidindo em tópicos como a frequência de 
questionamento nas aulas, o tipo e razões desse mesmo questionamento, as respostas dos professores às perguntas dos alunos ou possíveis barreiras ao processo.

\section{Análise dos dados}

Foi feita a análise de conteúdo das respostas dos participantes, tendo sido consideradas aas seguintes subcategorias: Importância das perguntas, Frequência de questionamento nas aulas, Tipo de perguntas, Razões para perguntar, Razões para não perguntar e Respostas dos professores.

\section{Resultados}

Todos os participantes no estudo, com exceção de três, consideraram importante a formulação de perguntas dos alunos, numa percentagem de $96.7 \%$ para o $\operatorname{Sim}, 2.3 \%$ para o Não e $1.1 \%$ As vezes.

No entanto, relativamente à Frequência e tipo de questionamento nas aulas verificou-se que, quando questionados sobre se costumavam fazer perguntas durante as aulas, 41.9\% dos alunos responderam que Sim, $27.9 \%$ dos participantes referiram que não fazem perguntas durantes as aulas e $24.4 \%$ que o fazem apenas às vezes (cf. Gráfico 1).

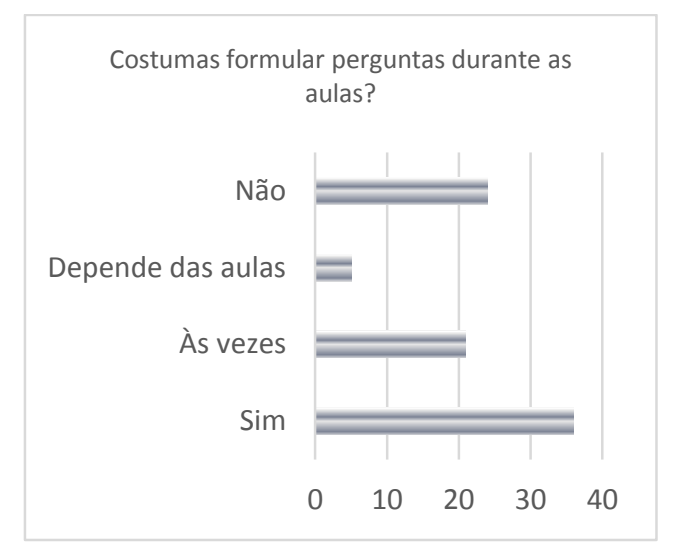

Gráfico 1. Perceção de formulação de perguntas durante as aulas

Os dados relativos ao Tipo de perguntas formuladas são referidos no Gráfico 2. Da sua análise, verifica-se que os tipos de perguntas mais frequentemente referidos são os que visam o Esclarecimento de dúvidas e Perceber melhor a matéria. Há também referência à formulação de perguntas Para saber mais, perguntas incidindo nos Como se faz ou no Porquê. São menos frequentes as referências a perguntas sobre a caracterização dos conceitos ou fenómenos ( $O$ que é? ) e perguntas de aplicação (Como aplico?).

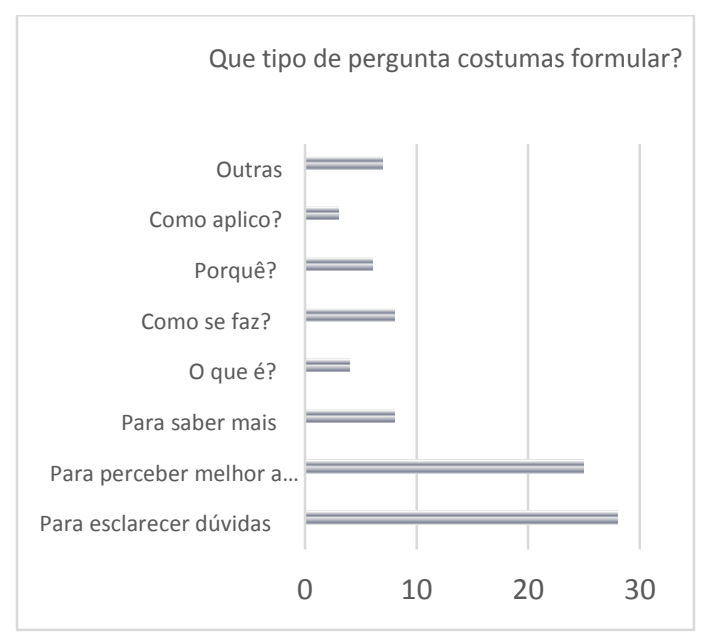

Gráfico 2. Tipo de perguntas formuladas durante as aulas

No Gráfico 3, apresentam-se os dados obtidos para a subcategoria Razões para perguntar que engloba os indicadores Dúvidas, Falta de compreensão, Para saber mais/curiosidade e Outras.

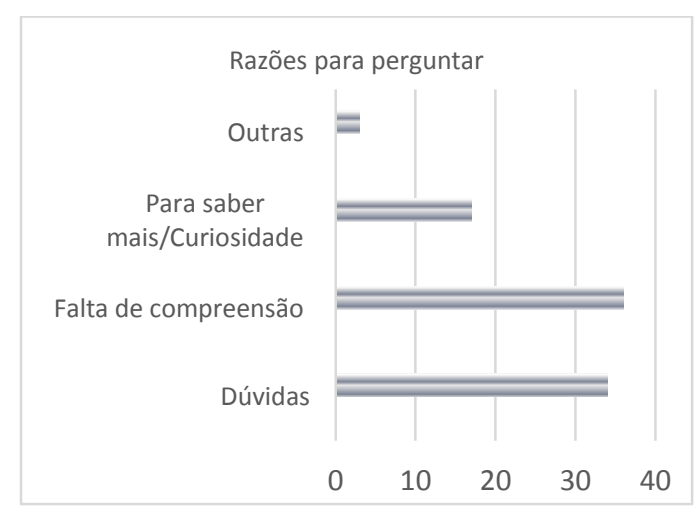

Gráfico 3. Razões para formular perguntas na aula

Uma análise do Gráfico 3 evidencia que a Falta de compreensão e Dúvidas constituem os indicadores predominantes nas razões para perguntar. De referir que os participantes referem também como motivo para a formulação de perguntas Querer saber mais/Curiosidade, embora este seja um motivo menos frequente que os anteriormente referidos.

Apresentam-se a seguir, no Gráfico 4, os dados obtidos para a subcategoria Razões para não perguntar, que engloba os indicadores Medo da reação do professor, Medo de ser gozado, Medo de ser considerado estúpido, Vergonha, Nada inibe a formulação de perguntas. 


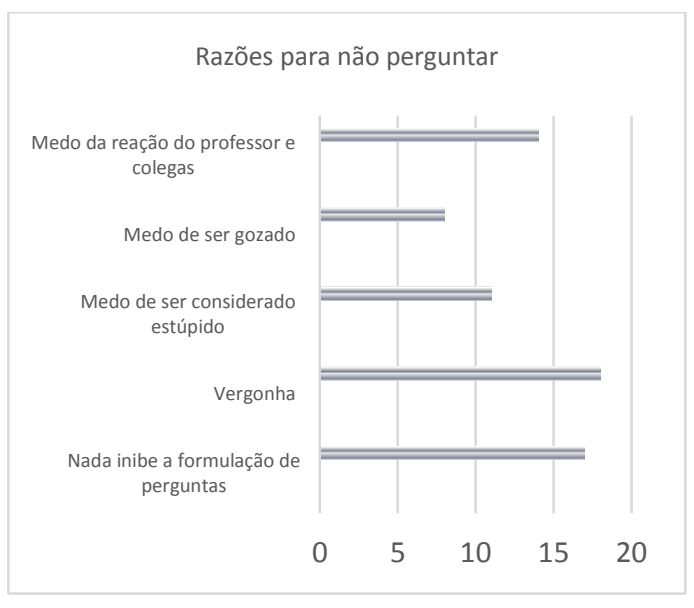

Gráfico 4. Razões para não formular perguntas na aula

O indicador referido mais frequentemente é o que aponta a Vergonha como razão para a não formulação de perguntas em contexto de aula. No entanto, são também expressivos os indicadores que exprimem Medo de ser gozado pelo professores ou colegas e Medo de ser considerado estúpido.

Relativamente à subcategoria Reações do professor às perguntas, a larga maioria dos alunos $(91 \%)$ relatam uma boa reação, referindo que os professores procuram esclarecer as dúvidas e explicar de novo os assuntos (cf. Gráfico 5).

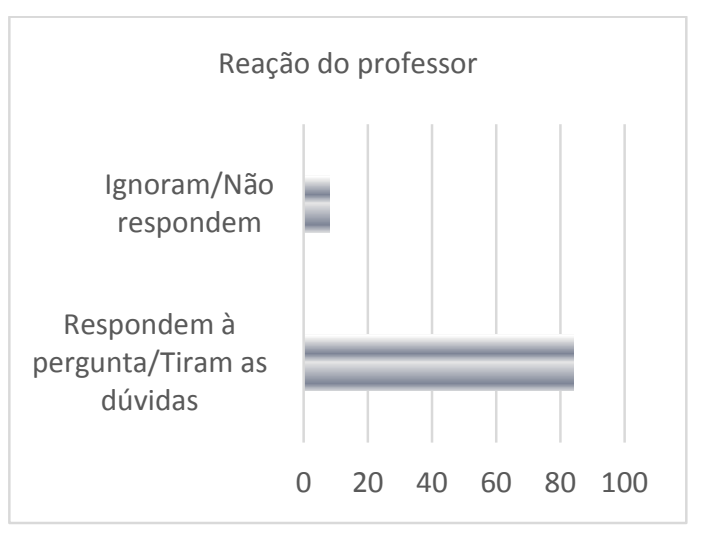

Gráfico 5. Razões para não formular perguntas na aula

No entanto, $9 \%$ dos alunos referem que os professores ignoram as suas perguntas, podendo mesmo ridicularizá-las.

\section{Conclusões}

A análise das perceções dos alunos relativamente ao questionamento em contexto de aula evidencia que aqueles consideram importante a formulação de perguntas, no entanto, mais de metade dos alunos que participaram no estudo referem também que não as formulam ou apenas $o$ fazem às vezes. Este desfazamento justifica o interesse pelas razões e motivos subjacentes à formulaçãode perguntas, tanto pelas razões que originam a sua formulação como pelas barreiras que a podem inibir. De acordo com os resultados obtidos, os alunos formulam perguntas em contexto de aula visando sobretudo esclarecer dúvidas e compreender melhor os assuntos. No entanto, formulam poucas perguntas por vergonha e também pelo receio da reação dos professores e dos colegas, pelo receio de ser considerado estúpido e ridicularizado. Isto apesar de considerarem que os professores procuram responder às questões que lhes são feitas e esclarecer as dúvidas colocadas. Os resultados obtidos apontam para razões divergentes subjacentes à formulação ou inibição do questionamento dos alunos, envolvendo aspectos predominantemente cognitivos para a formulação de perguntas e predominantemente sociais no caso da sua inibição. Estes dados vão de encontro aos mecanismos propostos por Graesser et al. (1992) para o processo de questionamento. No entanto, o desfazamento aqui constatado entre os motivos potenciadores e inibidores do questionamneto vem chamar particular atenção para os factores susceptíveis de os influenciar e suas interações, devendo ser explorado ao nível da dinâmica e gestão da aula, com implicações para a formação de professores.

\section{Referências bibliográficas}

Chin, C. \& Osborne, J. (2008) Students' questions: a potential resource for teaching and learning science, Studies in Science Education, 44:1, 1-39, DOI: $10.1080 / 03057260701828101$

Dillon, J.T. (1988). The remedial status of student questioning. Journal of Curriculum Studies, 20, 197210.

Graesser, A.C., Person, N.K. \& Huber, J.D. (1992). Mechanisms that generate questions. In T. Lauer, E. Peacock, \& A. C. Graesser (Eds.), Questions and information systems (pp. 167-187). Hillsdale, NJ: Erlbaum.

Graesser, A.C., \& Person, N.K. (1994). Question asking during tutoring. American Educational Research Journal, 31, 104-137.

Karabenick, S.A. (1996). Social influences on metacognition: Effects of colearner questioning on comprehension monitoring. Journal of Educational Psychology, 88, 689-703.

Otero, J. \& Ishiwa, K. (2014). Cognitive processing of ignorance. In D. N. Rapp y L.G. Jason (Eds.). Processing inaccurate information: Theoretical and applied perspectives from cognitive science and the educational sciences. Cambridge, Mass.: MIT Press.

Pedrosa de Jesus, H., Almeida, P., \& Watts, M. (2004). Questioning styles and students' learning: Four case studies. Educational Psychology, 24(4), 531-548.

Pedrosa de Jesus, H., Teixeira-Dias, J.J., \& Watts, M. (2003). Questions of chemistry. International Journal of Science Education, 25(8), 1015-1034.

Vaz-Rebelo, P., Fernandes, P., Morgado, J., Monteiro, A., Otero, J. (2014). Students' unknowns about natural objects and artifacts. Educational Psychology.

DOI: $10.1080 / 01443410.2014 .916398$

\section{Agradecimentos}

Este estudo teve o apoio da Comissão Europeia através do projeto nr. 531150-LP-2012-NL-KA3-KA3MP Multilateral KA3 Project SoNetTE: Social Networks in Teacher Education. 